\title{
Análise do concreto de pós reativos sustentável com dois diferentes tipos de areia
}

Ângela Costa Piccinini ${ }^{1}$

D01: http://dx.doi.org/10.18616/civiltec.v2i1.5353

Jonas Carvalho José2

\section{Introdução}

Devido às demandas do mercado da construção civil, novos materiais precisam ser desenvolvidos, seja em função da necessidade de maior capacidade de carga, de menor permeabilidade e de maior durabilidade, seja em função de quaisquer características necessárias para a sua aplicação (MALLMANN, 2013). Segundo Soto (2014), após o concreto convencional, já houve o desenvolvimento do concreto de alta resistência, do concreto de alto desempenho e, mais recentemente, do concreto de ultra alto desempenho. Os concretos de pós reativos (CPR) podem atingir resistências de um concreto de ultra alto desempenho. São concretos formados por partículas com diâmetro máximo menor que $2 \mathrm{~mm}$, que estão aplicados em elementos estruturais. O material oferece grandes resistências à compressão, à tração e, também, à flexão quando utilizada cura térmica (VANDERLEI, 2004). No CPR, por ser uma mistura composta por materiais de baixa granulometria, são eliminados os vazios da estrutura internamente, ganhando uma maior resistência e homogeneidade. A utilização do CPR em outros países já possibilitou construções mais leves, esbeltas, de baixo custo de manutenção e com maior vida útil. O custo e a metodologia de produção são as desvantagens. Com isso, este trabalho visa diminuir o custo da mistura de um CPR, além de presar pela parte ambiental, com a substituição de, aproximadamente, 35\% de cimento pela escória de alto forno, com dois tipos diferentes de areia. Não será utilizada cura térmica na produção.

\section{Metodologia}

O traço foi baseado na pesquisa de Yang et al. (2009). Os materiais constituintes do CPR foram cimento Portland CP-V ARI, escória de alto forno, sílica, areia, superplastificante

\footnotetext{
${ }^{1}$ Mestra, UNESC, acp@unesc.net

${ }^{2}$ Engenheiro, jocarjose@hotmail.com
} 
e relação água/cimento de 0,16 . Foram analisados 12 corpos de prova, sendo seis com areia $\mathrm{n}^{\circ} 50$ padronizada (retida na peneira $0,3 \mathrm{~mm}$ ), fornecida pelo Instituto de Pesquisa e Tecnologia (IPT), e seis com areia da região de Osório (RS), com diâmetro médio de $0,15 \mathrm{~mm}$. Os corpos de provas (CP) foram submetidos a ensaios de compressão axial aos sete e aos 28 dias.

\section{Resultados}

A resistência à compressão com areia do IPT aos sete dias foi de 73,49 $\mathrm{MPa}$, sendo $63,64 \%$ acima da resistência com a areia de praia. E aos 28 dias, com areia de praia, a resistência foi de 62,22 $\mathrm{MPa}$ e com areia do IPT foi de 84,7 MPa. Com relação à idade, 0 aumento foi maior - $38,54 \%$ - com a areia de praia dos sete aos 28 dias.

\section{Conclusões}

Por ser um concreto ecoeficiente, com menor consumo de cimento, reduzindo custo e impacto ambiental, os resultados encontrados foram satisfatórios, ficando acima da média para um concreto comum, e com maior durabilidade, por possuir menos vazios. Pôdese perceber que com a utilização de uma areia padronizada os resultados da resistência à compressão foram mais satisfatórios.

Palavras-chave: Concreto de pós reativos; Escória de alto forno; Areia padronizada.

\section{Referências}

MALLMANN, P. F. Concreto de Pós Reativos: Adição de Nanosílica. 2013. 67 f. Trabalho de Conclusão de Curso (Graduação em Engenharia Civil) - Universidade Federal do Rio Grande do Sul, Porto Alegre, 2013.

SOTO, N. T. A. Avaliação das propriedades do concreto de pós reativos: um estudo de durabilidade. 2014. 58 f. Monografia (Especialização em Patologias das Construções) Universidade Tecnológica Federal do Paraná, Curitiba, 2014.

VANDERLEI, R. D. Análise experimental do concreto de pós reativos: dosagem e propriedades mecânicas. 2004. 196 f. Tese (Doutorado em Engenharia de Estruturas) Universidade de São Paulo, São Carlos, 2004. 


\section{Revista Técnico-Cientifica

YANG, S. L.; MILLARD, S. G.; SOUTSOS, M. N.; BARNETT, S. J.; LE, T.T. Influence of aggregate and curing regime on the mechanical properties of ultra-high performance fibre reinforced concrete (UHPFRC). Construction and Building Materials, v. 23, n. 6, p. 2291-2298, 2009. 